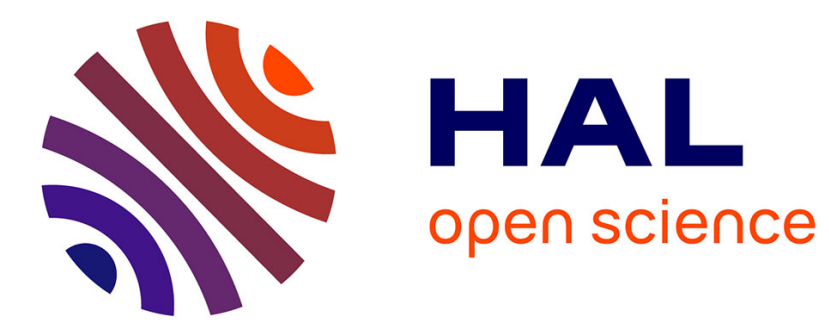

\title{
A 4.2 K Very High-Gain/Modulation Factor Silicon Detector/Modulator
}

\author{
E. Gutierrez-D., S. Koshevaya, P. Kolev, J. Deen
}

\section{To cite this version:}

E. Gutierrez-D., S. Koshevaya, P. Kolev, J. Deen. A 4.2 K Very High-Gain/Modulation Factor Silicon Detector/Modulator. Journal de Physique IV Proceedings, 1996, 06 (C3), pp.C3-213-C3-218. 10.1051/jp4:1996332 . jpa-00254250

\section{HAL Id: jpa-00254250 https://hal.science/jpa-00254250}

Submitted on 1 Jan 1996

HAL is a multi-disciplinary open access archive for the deposit and dissemination of scientific research documents, whether they are published or not. The documents may come from teaching and research institutions in France or abroad, or from public or private research centers.
L'archive ouverte pluridisciplinaire HAL, est destinée au dépôt et à la diffusion de documents scientifiques de niveau recherche, publiés ou non, émanant des établissements d'enseignement et de recherche français ou étrangers, des laboratoires publics ou privés. 


\title{
A 4.2 K Very High-Gain/Modulation Factor Silicon Detector/Modulator
}

\author{
E.A. Gutierrez-D. (1), S.V. Koshevaya, P. Kolev* and J. Deen* \\ National Institute for Astrophysics, Optics and Electronics (INAOE), P.O. Box 51 \& 216, Z.P. 72000 , \\ Puebla, Mexico \\ * Simon Fraser University, School of Engineering Science, Burnaby, B.C., V5A 1S6, Canada
}

\begin{abstract}
An n-well ion-implanted resistor is shown to work as a very-linear high-gain photodetector at $4.2 \mathrm{~K}$. We take advantage of freeze-out and light-assisted carrier ionisation effects to create a photodetector with a current-gain factor $G$ from $1 \times 10^{4}$ to $1.6 \times 10^{6}$. Experimental results show that at the current gain of $1.6 \times 10^{6}$, excellent linearity in optical response is obtained when the resistor is illuminated with a red-light source.
\end{abstract}

\section{INTRODUCTION}

Carrier freeze-out [1] is a well known effect that occurs in silicon having doping concentration levels below the degeneration level $\left(1 \times 10^{18} \mathrm{~cm}^{-3}\right)$. Thus for a non-degenerately doped silicon resistor, it is expected thay mobile carriers will be deeply frozen when operated at temperatures below about $30 \mathrm{~K}$ [2], [3]. This means that a silicon resistor will behave as an insulator, unless free carriers are provided by an external source. Under deep freeze-out conditions there are three different ways to provide free carriers; Poole-Frenkel Ionisation (PFI) [4], Field-Assisted Ionisation (FAI) [4], and Light-Assisted Ionisation (LAI) [4]. PFI starts playing a relevant role for carrier ionisation at temperatures above $15 \mathrm{~K}$. Below this critical temperature, under dark conditions, carriers can only be generated by applying an external electric field (FAI). Below $15 \mathrm{~K}$, and for applied voltages below the ionisation voltage $V_{c}$, the silicon resistor behaves as an insulator. Once the voltage is above $V_{c}$, some initial free carriers are generated which immediately give rise to carrier multiplication by avalanche, thus creating a large number of free carriers, which again results in the ohmic behavior.

We investigate how this ion-implanted resistor device reacts to light when operating in the insulating regime, and present some possible cryogenic application in the field of optical telecommunications, space detection and astronomy instrumentation.

\section{EXPERIMENTAL DETAILS}

A $1 \times 10^{17} \mathrm{~cm}^{-3} \mathrm{n}$-well implanted resistor with a $1.8 \mu \mathrm{m}$ junction depth, a width of $70 \mu \mathrm{m}$, and a length of $10 \mu \mathrm{m}$ was tested. The $\mathrm{p}$-substrate has the same doping concentration of $1 \times 10^{17} \mathrm{~cm}^{-3}$. The $\mathrm{n}^{+}$and $\mathrm{p}^{+}$contact regions have junction depths of $0.25 \mu \mathrm{m}$, and the field oxide on top of the n-well region is $650 \mathrm{~nm}$ thick. Measurements were performed using an HP4156A Parameter Analyzer, a closed-cycle refrigerator (at Simon Fraser University), and a open cycle cryostat LMT 500-Lakeshore (at INAOE).

The I-V characteristics of the $10 \mu \mathrm{m}$ length resistor with and without light, operated at $\mathrm{T}=4.2 \mathrm{~K}$, are shown in Fig.1. Under dark conditions the ionisation voltage $V_{c}$ is about $0.68 \mathrm{~V}$. For voltages below $V_{c}$ the resis-

(1) Contact author: On leave from INAOE, and currently at Simon Fraser University, School of Engineering Science, Burnaby, B.C., V5A 1S6, Canada 
tor remains completely frozen, without free carriers available for electrical conduction, therefore behaving as an insulator. The ionisation voltage is a linear function of the resistor length.

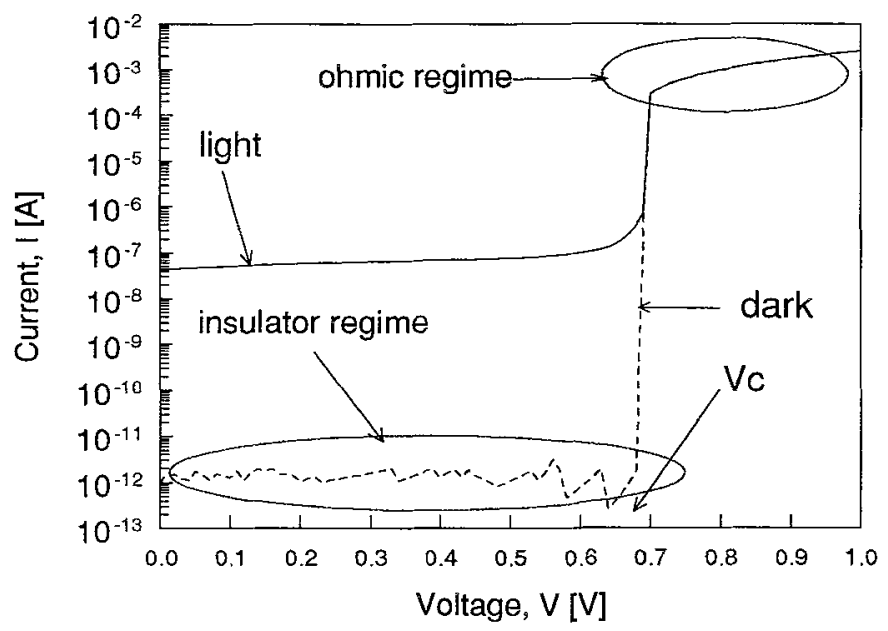

Figure 1: Current-voltage characteristics of the n-well resistor at $4.2 \mathrm{~K}$. The dashed line corresponds to dark- and the continuous one to light-conditions.

Once the voltage is above $\mathrm{V}_{\mathrm{c}}$, the resistor turns on from an off -current $\mathrm{I}_{\mathrm{off}}=1 \mathrm{pA}$ to an on-current $\mathrm{I}_{\text {on }}$ in the range of 1 to $5 \mathrm{~mA}$, and the ohmic regime is established. In this case the electric field $E$ has assisted carrier ionisation. The continuous line represents the current when the structure is illuminated with a $765 \mathrm{~nm}$ wavelength-laser diode.

The energy needed to create free carriers can be supplied with a light beam. The amount of free carriers generated can be controlled through the wavelength and the optical power. In this way, the structure may act, in general, as an optical detector with a very high photodetection gain.

The photodetection gain depends on the wavelength $\lambda$, the length between the two n-well contacts $L$, the surface n-well doping concentration $N$, the operating temperature $T$, and the n-well junction depth $X_{j}$.

The carrier conduction and the carrier flow distribution are depicted in Fig. 2. When the light beam comes through the structure, electron-hole pairs are generated in the silicon structure. The electrons flow towards the n-well contacts (VAR and REF), while the holes are swept towards the p-substrate contact (PSB). Four current paths are identified; 1) is the photo-electron current that flows into the VAR contact, 2) is the photo-electron current flowing into the REF contact, 3) is the photo-hole current that flows into the PSB contact, and 4) is the electron current that flows between the REF and VAR contacts, when a potential difference $\left(\mathrm{V}_{\text {var }}-\mathrm{V}_{\text {ref }}\right)$ exists between these two contacts. It is worth mentionning that the photo-electron current splits into two branches unequally. This means more electrons are swept towards the VAR contact than to the REF contact. This unbalanced flow becomes more pronnounced when the $V_{v a r}$ voltage starts sweepping from 0 to $1 \mathrm{~V}$, while $\mathrm{V}_{\text {ref }}$ is kept constant at $0 \mathrm{~V}$. The carrier conduction in the structure exposed to redligth is shown in Fig. 3. In the insulator regime, the current $I_{v a r}$ stays increasing linearly as the 
voltage $\mathrm{V}\left(\mathrm{V}_{\mathrm{var}}-\mathrm{V}_{\text {ref }}\right)$ is swept from 0 to $1 \mathrm{~V}$. The $\mathrm{I}_{\text {ref }}$ current is positive from 0 to about $0.5 \mathrm{~V}$, then it becomes negative, while the hole current $I_{p s b}$ keeps negative and increasing in value, when the voltage is swept from 0 to $1 \mathrm{~V}$. The $\mathrm{I}_{\text {ref }}$ current changes of sign because the absolute value of the current flowing between the var and ref contacts becomes higher than the current component 2.

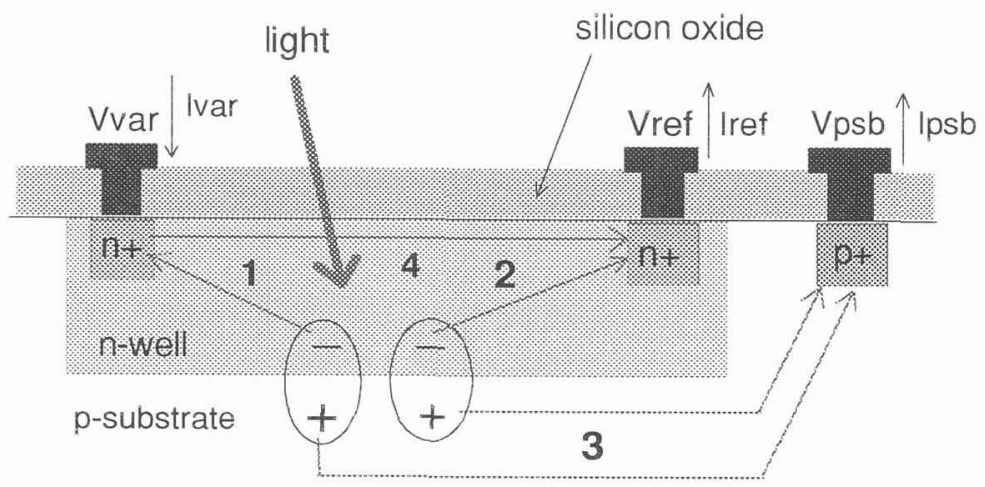

Figure 2: Schematic representation of the n-well resistor with 4 current components identified; 1) photo-electrons sinked to the REF contact, 2) photo-electrons drained to the VAR contact, 3) photo-holes sinked to the PSB contact, and 4) the electrons that flow between the REF and VAR contacts.

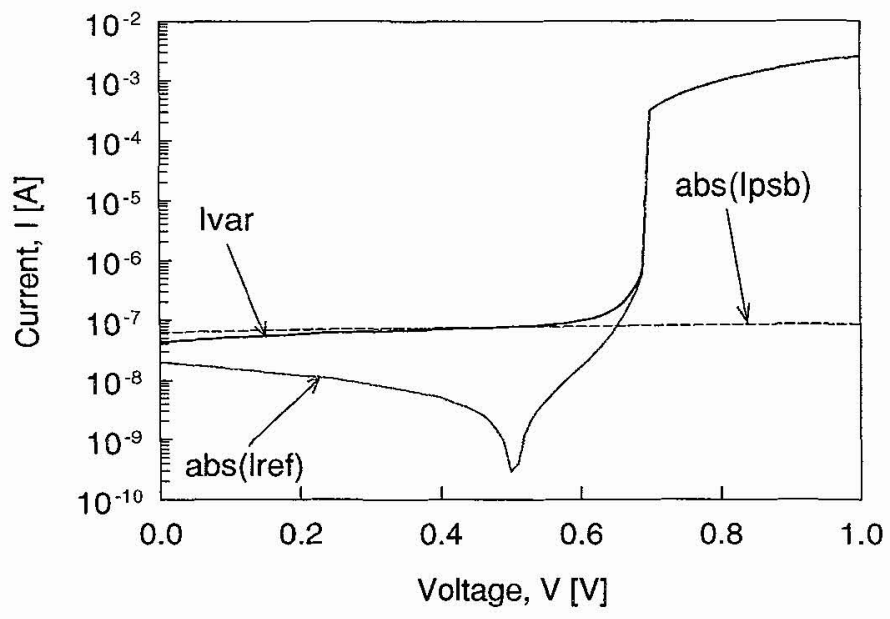

Figure 3: Current-voltage characteristics of the n-well resistor under illumination. The dashed line corresponds to the absolute value of p-substrate current $\mathrm{I}_{\mathrm{psb}}, \mathrm{I}_{\mathrm{var}}$ is the current measured at the VAR contact, and abs $\left(\mathrm{I}_{\mathrm{ref}}\right)$ is the absolute value of the current measured at the REF contact.

To investigate the influence of the optical power on the I-V characteristics, the power consump- 
tion of the laser diode was varied from 85 to $765 \mathrm{~mW}$. The I-V characteristics in the ohmic regime are not affected by the light. Therefore, in Fig. 4 only the insulator regime is shown. Under dark conditions, the current in the insulator regime isat the picoampere level. This means that for the highest light intensity (curve $i$ ) the gain current $\left(\mathrm{I}_{\text {light }} / \mathrm{I}_{\mathrm{dark}}\right) G$ is about $1.6 \times 10^{6}$ at $\mathrm{V}=0.4 \mathrm{~V}$.

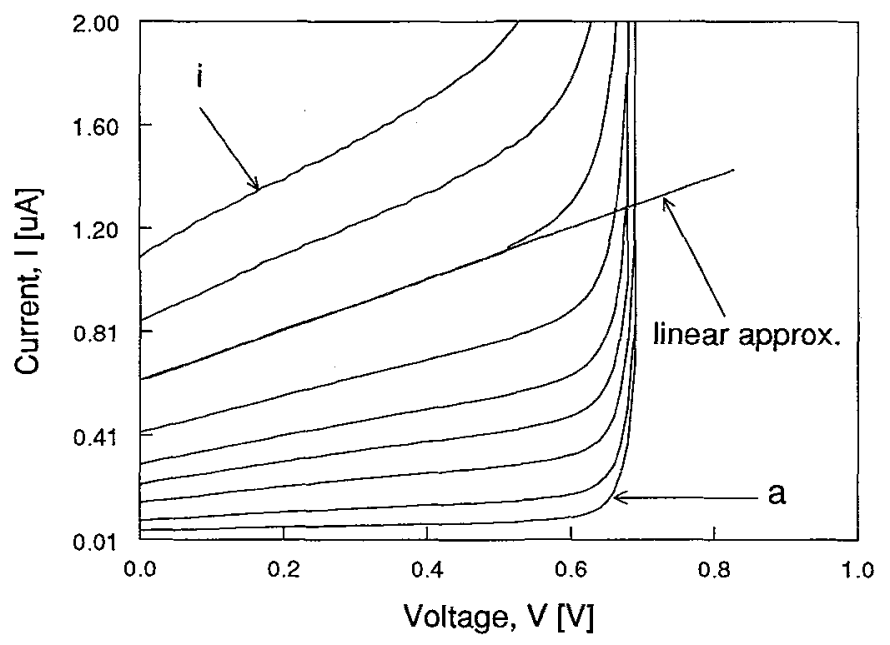

Figure 4: Experimental I-V characteristics under different light intensities. Plot $a$ corresponds to the lowest light intensity. The straight line is a linear approximation in the 0 to $0.4 \mathrm{~V}$ range.

Under illumination, the insulator region ( 0 to $0.7 \mathrm{~V}$ ) becomes ohmic. This ohmic behavior is indicated with the straight line between 0 and $0.4 \mathrm{~V}$. At higher voltages, the FAI mechanism starts influencing the structure, which can be observed from the deviation of the linear curve towards an exponential behavior.

Finally, the insulator-regime conductance $g_{i n}$, in the $0.0-0.4$ voltage range, versus laser power consumption $P$ is shown in Fig. 5. The open squares corresponds to experimental data, and the line is a linear fit. A transresistance $g_{r}$ of $4.53 \times 10^{8} \Omega / \mathrm{mW}$ is extracted out of the linear fit. At present we have not characterised the light intensity (or optical power) versus power consumption of the laser at $4.2 \mathrm{~K}$.

The experimental results shown in Fig. 5 indicates that this device is effectively acting as a transistor, with the $n^{+}$ref contact as source terminal , the $n^{+}$var contact as drain terminal, the $p^{+}$contact as substrate terminal, and the light beam as a gate. In this case, the channel and its conductance are controlled by the amount of photoinjected electrons, with the amount of photoelectrons depending on the light beam energy and its optical power. In analogy to a MOS transistor, here one has a Light-Oxide-Silicon-CryoTransistor (LOSCT), with a current gain $G$ as large as $1.6 \times 10^{6}$ in the linear portion $(0.0-0.4 \mathrm{~V})$ of the $\mathrm{V}_{\mathrm{var}}$ voltage, and a optical-to-electrical conductance $g\left(\mathrm{I}_{\mathrm{var}} / \mathrm{P}\right)$ of about $2.0 \times 10^{-2} \mu \mathrm{A} / \mathrm{mW}$.

With the above electrical/optical characteristics, this cry-optical odevice can be used as a veryhigh-gain detector. As a modulator it can be used to modulate microwave signals [7 ] that have to pass through the frozen region. The refraction index of the $n$-well silicon is controlled by the 
amount of electrons injected to the frozen region.

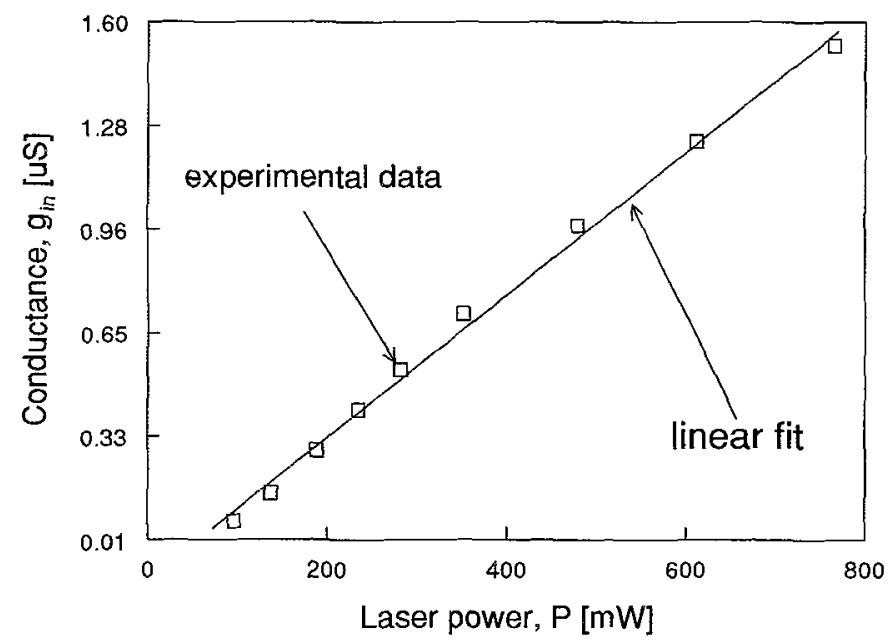

Figure 5: Experimental insulator-regime conductance $g_{\text {in }}$ versus laser power $P$ at $4.2 \mathrm{~K}$. The device voltage is varied from 0 to $0.4 \mathrm{~V}$.

The speed response of this photodevice is currently under investigation, and more results will be presented later.

\section{CONCLUSION}

A n-well implanted resistor, operated at $4.2 \mathrm{~K}$ in the insulator regime, has been electrically and optically characterized, and proven to operate as an optical detector with a gain as large as $1.6 \times 10^{6}$, and with a very good Current-Voltage linearity. The optical-to-electrical conductance $g_{o e}$ $\left(\Delta \mathrm{I}_{\mathrm{var}} / \Delta \mathrm{P}\right)$ is found to be $2.0 \times 10^{-2} \mu \mathrm{A} / \mathrm{mW}$, with an excellent $\mathrm{I}-\mathrm{V}$ linearity in the $0.0-0.4 \mathrm{~V}$ range. In the linear region, and at a maximum gain, the power dissipation is $0.68 \mu \mathrm{W}$, which makes this device an excellent choice for low-power consumption.

\section{Acknowledgments}

Devices used here were provided by the Interuniversity Microelectronics Center (IMEC), Leuven, Belgium. Measurements were done through a bilateral research collaboration between the Department of Electronics of the National Institute of Astrophysics, Optics and Electronics (INAOE), Puebla, Mexico, and the Integrated Devices and Circuits Research Laboratory (Prof. Jamal Deen) at the School of Engineering Science of the Simon Fraser University, Burnaby, Canada. The two first authors are grateful to the National Council for Science and Technology-Mexico (CONACyT), for supporting this work. 


\section{References}

[1] D. P. Foty, "Impurity ionization in MOSFETs at very low temperatures", Cryogenics, Vol. 30 , pp. 1056-1063, December, 1990.

[2] E. Simoen, B. Dierickx, L. Deferm, C. Claeys, and G. Declerck, "The charge transport in a silicon resistor at liquid helium temperatures", J. Appl. Phys., 68, pp. 4091-4099, 1990.

[3] E. A. Gutierrez-D., L. Deferm, and G. Declerck, "Selfheating effects in silicon resistors at cryogenic ambient temperatures", Solid-State Electronics, Vol. 36, No. 1, pp. 41-52, 1993.

[4] S. M. Sze, "Physics of semiconductor devices", 2ndd ed., Wiley, New York, 1981.

[5] V. V. Grimalsky, Ya. I. Kishenko, S. V. Koshevaya, and E. A. Gutierrez-D, "An integrated surface-oriented P-I-N device designed for quasi optical modulation", Proceedings ESSDERC'95, pp. 281-284, 1995. 